\title{
Pristine and Al-doped hematite printed films as photoanodes of $p$-type dye-sensitized solar cells
}

\author{
Mirko Congiu • Maria L. De Marco • \\ Matteo Bonomo • Oswaldo Nunes-Neto • Danilo Dini • \\ Carlos F.O. Graeff
}

Received: 30 June 2016/Accepted: 14 December 2016 / Published online: 24 December 2016

(C) Springer Science+Business Media Dordrecht 2016

\begin{abstract}
We hereby propose a non-expensive method for the deposition of pure and Al-doped hematite photoanodes in the configuration of thin films for the application of dye-sensitized solar cells (DSSC). The electrodes have been prepared from hematite nanoparticles that were obtained by thermal degradation of a chemical precursor. The particles have been used in the preparation of a paste, suitable for both screen printing and doctor blade deposition. The paste was then spread on fluorine-doped tin oxide (FTO) to obtain porous hematite electrodes. The electrodes have been sensitized using N3 and D5 dyes and were characterized through current/voltage curves under simulated sun light (1 sun, AM 1.5) with a Pt counter electrode. Aldoping of hematite showed interesting changes in the physical and electrochemical characteristics of sensitized photoanodes since we could notice the growth of
\end{abstract}

Electronic supplementary material The online version of this article (doi:10.1007/s11051-016-3707-4) contains supplementary material, which is available to authorized users.

M. Congiu $(\bowtie) \cdot$ O. Nunes-Neto $\cdot$ C. F. Graeff

UNESP-Univ. Estadual Paulista, POSMAT-Programa de

Pós-Graduação em Ciência e Tecnologia de Materiais, Av. Eng.

Luiz Edmundo Carrijo Coube14-01, Bauru, SP 17033-360, Brazil

e-mail: mirko.congiu@fc.unesp.br

M. L. De Marco • M. Bonomo • D. Dini

DC-FC-UNESP-Univ. Estadual Paulista, Av. Eng. Luiz Edmundo

Carrijo Coube14-01, Bauru, SP 17033-360, Brazil

C. F. Graeff

Department of Chemistry, University of Rome "La Sapienza",

Piazzale Aldo Moro 5, Rome, RM, Italy
$\mathrm{AlFe}_{2} \mathrm{O}_{4}$ (hercynite) as a secondary crystal phase into the oxides obtained by firing the mixtures of two chemical precursors at different molar ratios. Pure and Aldoped hematite electrodes have been used in a complete $n$-type DSSCs. The kinetics of charge transfer through the interface dye/electrolyte was studied and compared to that of a typical $p$-type DSSC based on NiO photocathodes sensitized with erythrosine $\mathrm{B}$. The results suggest a potential application of both $\mathrm{Fe}_{2} \mathrm{O}_{3}$ and $\mathrm{Fe}_{2} \mathrm{O}_{3}$ / $\mathrm{AlFe}_{2} \mathrm{O}_{4}$ as photoanodes of a tandem DSSC.

Keywords Hematite - Al-doped · Dye solar cell · Hercynite $\cdot$ Tandem solar cell $\cdot$ Energy conversion

\section{Introduction}

Dye-sensitized solar cells (DSSCs) (O'regan and Gräzel 1991) are photoelectrochemical cells which represent an advanced technology of solar conversion with low costs of fabrication and efficiencies up to 13\% (Mathew et al. 2014). A typical DSSC configuration consists of a mesoporous semiconductor deposited on a transparent conductive oxide layer (TCO). An organic or organometallic dye is anchored on the surface of the semiconductor and is responsible for light harvesting through the promotion of electrons from the HOMO to the LUMO level of the dye sensitizer. Such an excitation generates charge carriers (electron and hole) at the dyesemiconductor interface thus generating a photopotential. In a $n$-type DSSC, the promoted electron of the excited dye is injected into the conduction band of 
the mesoporous semiconductor $\left(\mathrm{TiO}_{2}\right.$ or $\left.\mathrm{ZnO}\right)$. Successively, a redox mediator transfers an electron to regenerate the oxidized dye and is converted into its oxidized form. Contrariwise, in a $p$-type solar cell, the excited electrons of the dye are transferred directly to the redox mediator while the hole is injected in the valence band of the photocathode, namely $\mathrm{NiO}$ (Awais et al. 2011; Bonomo; Dini 2016a; Congiu et al. 2016a). In both $p$ and $n$-type DSSCs, the redox mediator is regenerated at the counter-electrode (CE) which consists of a thin layer of catalytic material. Usually, a thin layer of platinum nanoparticles is used as CE for DSSCs (Fu et al. 2012; Lan et al. 2010). However, Pt is an expensive and scarcely available material and its employment in DSSCs influences heavily the overall costs of such devices. Cheaper and more abundant materials, such as $\mathrm{CoS}$, could be used to replace Pt CEs in DSSCs (Congiu et al. 2015a, 2015b, 2016b). However in most applications, CE is not a photoelectroactive element and it serves just as a catalyst for the electrolyte regeneration (De Rossi et al. 2013; Wang and $\mathrm{Hu}$ 2012; Wang et al. 2009). A modern strategy to enhance the performance of a DSSC is the adoption of the tandem cell configuration, first proposed by He et al., which consists in the replacement of the CE with a dye-sensitized $p$-type electrode (He et al. 2000). In this configuration, the $n$-type photoanode is coupled with a $p$-type photocathode in order to improve the cells performance and enhance the photovoltage (De Vos 1980). However, the efficiency of the $p$-type side is still too low in comparison with the $n$ side, and this leads to a non-cumulative efficiency in tandem configuration (Awais et al. 2011; Bonomo and Dini 2016b). Therefore, the use of a sensitized NiO photocathode in tandem with a sensitized $\mathrm{TiO}_{2}$ photoanode, after all, results in a reduction of the performance of the DSSC with the sole photoactive anode. This is mainly due to the lower photocurrent generated by the $\mathrm{NiO}$ chatode, which limits the value of the maximum current of the device. In the tandem configuration, the photoanode and the photocatode are in series, and the maximum current obtainable is the value of current produced by the less efficient electrode. In this research context, the study of photoelectroactive anodes based on cheap and earth-abundant semiconductors is of great interest and is beneficial to the optimization of DSSCs of the tandem type. As photoactive anode hematite represents an ideal candidate since it is a cheap and widely available and displays interesting electrical and optical properties, in fact, hematite possesses semiconducting properties with an optical band gap of $2.1 \mathrm{eV}$ and $n$-type behavior in most applications (Kumar et al. 2012; Tamirat et al. 2016). The concentration and the nature of charge carriers (electrons) are determined by the existence of oxide vacancies into the lattice (Miller et al. 2004). In particular conditions, it is possible to obtain also hematite of $p$-type as reported by Lin et al., who succeeded in the synthesis of $p$-type hematite via atomic layer deposition and $\mathrm{Mg}$-doping (Lin et al. 2012). In this work, we investigated the electrochemical properties of porous layers of hematite $\left(\alpha-\mathrm{Fe}_{2} \mathrm{O}_{3}\right)$, obtained by thermal decomposition of a chemical precursor based on an acetylacetonate (Willis et al. 2007). Through the use of a printing system and a large area deposition method, we could obtain nanostructured layers of $\alpha-\mathrm{Fe}_{2} \mathrm{O}_{3}$ nanoparticles. In order to study a possible strategy for the improvement of the photoelectrochemical performance of hematite, the doping of iron oxide with different concentrations of aluminum $(\mathrm{Al})$ was considered. Aluminum doping can increase the optical band gap of hematite (Lin et al. 2011). Furthermore, there are several evidences on the improvement of the hematite performance as anode of photoelectrochemical cells induced by Al-doping (Lin et al. 2011; Shinde et al. 2011). The generation of an anodic current in photoelectrochemical cells for watersplitting confirms the $n$-type nature of both pure and Aldoped hematite (Kumar et al. 2012; Shinde et al. 2011). The electrodes were sensitized with two different dyes: one based on Ru (N3) and the organic D5. Complete $n$ type DSSC cells have been fabricated and characterized using sensitized hematite photoanodes. By means of electrochemical impedance spectroscopy (EIS), the charge transfer kinetics at the interface photoanode/ electrolyte has been studied. The results showed a recombination kinetics very close to that observed in a typical $p$-DSSC based on a mesoporous NiO photocathode which is sensitized by erythrosine $\mathrm{B}$.

\section{Materials and methods}

Iron (III) chloride, potassium iodide $(\mathrm{KI})$, iodine $\left(\mathrm{I}_{2}\right)$, absolute ethanol (EtOH), $\alpha$-terpineol, ethyl cellulose (EC), acetylacetone (acac), erythrosine B (ERY), cisBis (isothiocyanato) bis (2,2'-bipyridyl-4,4'dicarboxylato ruthenium (II) (N3), and fluorine doped tin oxide coated glass slides (FTO $\sim 7 \Omega / \square$ ) were purchased from Sigma-Aldrich and were used as received. 
D5 dye (3-(5-(4-(diphenylamino) styryl) thiophen-2-yl)2-cyanoacrylic acid) was supplied by Dyenamo, Sweden. X-Ray diffraction patterns (XRD) were collected on powder samples with a DMAX Ultima (Rigaku International Corporation, Tokyo, Japan), operating at $40 \mathrm{kV}$ and $2 \mathrm{~mA}$. Scans were performed from $5^{\circ}$ to $80^{\circ}$ with a step size of $0.02^{\circ}$ at the scan speed of $2 \%$ min. Confocal optical microscopy measurements were performed using a Leica DCM 3D Dual Core 3D Measuring Microscope. Imaging with 3D topography allowed the graphical evaluation of the mean square roughness of the surface (RMS) of the hematite electrodes. The surface of the electrodes was also characterized using an atomic force microscopy (AFM) of the type Park Systems XE7. The measurements were performed in the contact mode through the scanning of $X, Y$-directions to avoid artifacts. The AFM tip was from PPP-CONSTCR Nanosensors and had a force constant of $0.2 \mathrm{~N} / \mathrm{m}$ and radius $<10 \mathrm{~nm}$. The AFM tip worked at the resonance frequency of $23 \mathrm{kHz}$. EIS spectra were collected on symmetric devices at $0 \mathrm{~V}$ with a sinusoidal modulation of $10 \mathrm{mV}$ from $100 \mathrm{mHz}$ to $100 \mathrm{kHz}$. The EIS characterization was performed with an Autolab PGStat 300, which was equipped with a FRA32 impedance board. Cyclic voltammetry (CV) was carried out utilizing the same equipment of EIS determinations. Voltammograms were recorded varying the applied potential from -1.0 to $1.0 \mathrm{~V}$ at different scan rates. Current vs voltage curves (JV) have been performed in order to calculate the principal photovoltaic (PV) parameters: fill factor (FF), short circuit current $\left(\mathrm{J}_{\mathrm{sc}}\right)$, open circuit voltage $\left(\mathrm{V}_{\mathrm{oc}}\right)$, and efficiency ( ). For further information about PV parameter calculation, please see electronic supplementary material (S.1.).

Preparation of $\alpha-\mathrm{Fe}_{2} \mathrm{O}_{3}$ nanoparticle paste

Iron (III) acetylacetonate $\left(\mathrm{Fe}(\mathrm{acac})_{3}\right)$ has been synthesized with the following procedure: $0.33 \mathrm{~g}$ of finely ground $\mathrm{FeCl}_{3} \cdot 6 \mathrm{H}_{2} \mathrm{O}$ were dissolved in $2.5 \mathrm{~mL}$ of distilled water. A fresh-prepared solution of $0.38 \mathrm{~g}$ of acetylacetone in $10 \mathrm{~mL}$ of methanol was slowly dropped into the main solution under stirring. A solution of $0.51 \mathrm{~g}$ of sodium acetate was slowly dropped under stirring into the resulting solution. The mixture was then heated to $80{ }^{\circ} \mathrm{C}$ on a hotplate for $15 \mathrm{~min}$ and cooled down to room temperature through its immersion in an ice bath. Red crystals were obtained and were separated by suction filtration. The product was washed with cold water and ethanol and finally dried under vacuum. Al (acac) 3 was prepared following the same procedure described above, using $\mathrm{Al}_{2}\left(\mathrm{SO}_{4}\right)_{3}$ instead of $\mathrm{FeCl}_{3}$. Al-doped nanoparticles were obtained by mixing $\mathrm{Al}$ $(\mathrm{acac})_{3}$ with $\mathrm{Fe}(\mathrm{acac})_{3}$ in different percentages $(0,1$, 5 , and $10 \% \mathrm{w} / \mathrm{w}$ ) prior to thermal degradation. In order to mix efficiently the precursors, the exact quantities were dissolved in a minimum aliquot of acetone; then, the solvent was slowly evaporated and the resulting powder was finally grinded in a mortar. Spherical $\alpha$ $\mathrm{Fe}_{2} \mathrm{O}_{3}$ and $\mathrm{Al}_{\mathrm{x}} \mathrm{Fe}_{2-\mathrm{x}} \mathrm{O}_{3}$ nanoparticles (NPs) have been obtained by firing the mixtures of the chemical precursors in a ceramic crucible at $450{ }^{\circ} \mathrm{C}$ for $30 \mathrm{~min}$. A ceramic plate was placed under the crucible to avoid any spills into the oven. The obtained products were finely grinded using an agate mortar. In a plastic container, $30 \mathrm{mg}$ of grinded $\alpha-\mathrm{Fe}_{2} \mathrm{O}_{3}$ or $\mathrm{Al}_{\mathrm{x}} \mathrm{Fe}_{2-\mathrm{x}} \mathrm{O}_{3} \mathrm{NPs}$ were dispersed in $300 \mu \mathrm{L}$ of absolute ethanol, and then, $30 \mathrm{mg}$ of EC were added to the slurry. The vessel was transferred in an ultrasound bath and kept in it for $30 \mathrm{~min}$. After the addition of $200 \mu \mathrm{L}$ of deionized water, the sonication step was repeated. Finally, $20 \mu \mathrm{L}$ of a $50 /$ 50 mixture of acetyl acetone and $\alpha$-terpineol was added to the slurry. After the addition, the paste was sonicated for more than $30 \mathrm{~min}$. If aggregates are formed, a glass rod should be used to mix the paste.

Deposition of hematite electrodes

FTO $(2 \times 2 \mathrm{~cm})$ square glass slides were thoroughly cleaned using an ultrasonic bath with three different solvents: distilled water, acetone, and isopropanol. Finally, the substrates were dried and used without other treatments. A conventional adhesive tape was used to delimitate a rectangular deposition area of $0.25 \mathrm{~cm}^{2}$. The paste was then spread on each substrate using a glass slide (doctor blade). The deposited films were dried for 20 min till the complete evaporation of ethanol. After removing the tape mask, the electrodes were transferred into a muffle and annealed at $450{ }^{\circ} \mathrm{C}$ for $30 \mathrm{~min}$ in order to eliminate all organic components and effectuate the sintering of the metal oxide nanoparticles.

Photoanode sensitization

After the thermal treatment, the oxide films were cooled to $80{ }^{\circ} \mathrm{C}$ and rapidly immersed in a solution of D5 in ethanol for $16 \mathrm{~h}$. The sensitizing solution of D5 had a mass concentration of $1 \mathrm{mg} / \mathrm{mL}$. The sensitized 
photoanodes were washed several times with absolute ethanol and dried under vacuum. Finally, the electrodes were sealed with a Pt CE using a hot-melt spacer ( $35 \mu$, Bynel $\left.{ }^{\circledR}\right)$. The iodine-based liquid electrolyte HSEBV12 (Dyers, Roma) was injected by vacuum backfilling. The sealed cells were let to stabilize for $1 \mathrm{~h}$ in dark conditions. The determination of the JV curves was realized on the closed DSSCs.

Photometric determination of $\mathrm{Fe}^{3+}$ and $\mathrm{Al}^{3+}$

The oxide samples were obtained as powders from the procedures described in previous paragraphs. Ten milligrams of oxide was dissolved into $40 \mathrm{~mL}$ of concentrated $\mathrm{HCl}(37 \%)$ with the addition of $1 \mathrm{~mL}$ of hydrogen peroxide $(20 \%)$. The solution was diluted to a final volume of $100 \mathrm{~mL}$ with Milli-Q water. The concentrations of both $\mathrm{Fe}$ and $\mathrm{Al}$ were determined using the photometer Alkafit Superfoto (SN. E008145).

Thiocyanate $\left(\mathrm{SCN}^{-}\right)$was used as colorimetric indicator at fixed wavelengths for the determination of $\mathrm{Fe}^{3+}$ (480 nm, blue filter), while eriochrome cyanine was the indicator of $\mathrm{Al}^{3+}$ (535 nm, green filter) (Dougan and Wilson 1974; Shull and Guthan 1967). Molar concentrations of $\mathrm{Fe}$ and $\mathrm{Al}$ were calculated using calibration curves.

\section{Results and discussion}

The powder obtained by thermal degradation of pure $\mathrm{Fe}$ $(\text { acac })_{3}$ was characterized through X-ray diffraction (XRD) spectroscopy in order to determinate the phase and the average size of the $\mathrm{Fe}_{2} \mathrm{O}_{3}$ crystals. As shown in Fig. 1, the powder presents just the hematite phase without other phases of $\mathrm{Fe}$ (III) oxide. The pattern shown by the powder is typical of hematite $\alpha-\mathrm{Fe}_{2} \mathrm{O}_{3}$ (JCPDS 86-0550). Narrow peaks indicate the presence of most nanosized material. When $\mathrm{Al}(\mathrm{acac})_{3}$ was added into precursor mixture, the XRD patterns of the powders obtained by thermal degradation indicated the existence of a second crystal phase. Three new peaks at $30.4^{\circ}$, $43.5^{\circ}$, and $63.1^{\circ}$ were assigned, respectively, to (220), (400), and (440) planes of $\mathrm{AlFe}_{2} \mathrm{O}_{4}$ (hercynite JCPDS 007-0068) (Fukushima et al. 2013; Jastrzębska et al. 2015). The peak at 57.5 can be assigned to both $\alpha$ $\mathrm{Fe}_{2} \mathrm{O}_{3}$ and $\mathrm{AlFe}_{2} \mathrm{O}_{4}$. It corresponds to planes (122) and (422), respectively. Such a peak becomes more intense and broader upon addition of increasing amounts of Al.
The XRD peaks associated to $\mathrm{AlFe}_{2} \mathrm{O}_{4}$ are broader in comparison with those of $\alpha-\mathrm{Fe}_{2} \mathrm{O}_{3}$. This suggests that the average crystal size of $\mathrm{AlFe}_{2} \mathrm{O}_{4}$ is lower than that of $\alpha-\mathrm{Fe}_{2} \mathrm{O}_{3}$. Sherrer equation has been used to calculate the average crystal size of both hercynite and hematite. Full widths at half maximum (FWHM) of the peaks were calculated by fitting each of them with a Gaussian function. The resulted average crystal sizes calculated for $\alpha-\mathrm{Fe}_{2} \mathrm{O}_{3}$ were $32.6 \mathrm{~nm}$ for pure hematite and 27.4, 27.7 , and $28.6 \mathrm{~nm}$ for the powders obtained by firing the mixtures containing 1,5 , and $10 \%(w / w)$ of $\mathrm{Al}(\mathrm{acac})_{3}$, respectively. From the peaks at $30.4^{\circ}$ and $43.5^{\circ}$ (Fig. $1 \mathrm{~b}$, $\mathrm{c}, \mathrm{d}$ ), we calculated the average size of $\mathrm{AlFe}_{2} \mathrm{O}_{4}$ crystals: $10.8 \mathrm{~nm}$. The latter signals are assigned to hercynite phase.

As a result, the presence $\mathrm{AlFe}_{2} \mathrm{O}_{4}$ leads to a reduction of the average crystal size of $\alpha-\mathrm{Fe}_{2} \mathrm{O}_{3}$ into the mixed oxide phase. From the hematite peaks of the planes (104) and (110) at 33.2 and $35.6^{\circ}$, respectively (Fig. 1a), one can notice an Al-dependent variation of their relative intensities. In fact, in pure hematite, the peak at $33.2^{\circ}$ is the more intense signal of the pattern. The addition of $\mathrm{Al}$ leads to a systematic reduction of peak intensity at $33.2^{\circ}$ and to the increase of that at $35.6^{\circ}$. Looking at the pattern of Fig. 1d, the peak at 35.6 becomes the more intense signal. This suggests that $\mathrm{Al}$ influences the preferred orientation of $\alpha-\mathrm{Fe}_{2} \mathrm{O}_{3}$ crystals when $\mathrm{Al}(\mathrm{acac})_{3}$ weight ratio is higher than $5 \%(w / w)$.

\section{Quantification of aluminum}

The percentage in weight ratio $(w / w)$ of aluminum in oxide samples was obtained by photometric measurements. The chemical analysis results are resumed in Table 1 and compared with the predicted (theoretical) compositions. The latter are calculated through the mass ratios of chemical precursors in the mixture. Notice that aluminum and iron acetylacetonates have different molecular weights: 324.31 and $353.17 \mathrm{~g} \mathrm{~mol}^{-1}$, respectively.

As shown in Table 1, mixtures B, C, and D led to the production of oxides with different Al-content. The Al/ Fe mass ratio, determined through photometry measurements, showed values close to those calculated considering the composition of mixtures A, B, C, and D. Since XRD patterns have shown the presence of $\mathrm{AlFe}_{2} \mathrm{O}_{4}$ (hercynite), it is important to consider that in this phase, iron is present as both $\mathrm{Fe}^{2+}$ and $\mathrm{Fe}^{3+}$ (Fukushima et al. Takizawa 2013; Jastrzębska et al. 2015). Thus, the 
Fig. 1 X-ray diffraction pattern of the powders obtained by firing the mixtures of the chemical precursors at $400{ }^{\circ} \mathrm{C}$ during $30 \mathrm{~min}$. a The XRD diffraction pattern obtained when no $\mathrm{Al}(\mathrm{acac})_{3}$ was present displays the characteristic peaks of hematite (white diamond) (JCPDS 860550). The Miller indexes of the diffraction planes ( $\mathrm{h} \mathrm{k}$ l) for pure hematite are on going from left to right in the spectrum: (012), (104), (110), (113), (024), (116), (122), (214), and (300).

Diffraction peaks (black star) of $\mathrm{AlFe}_{2} \mathrm{O}_{4}$ (hercynite JCPDS 0070068) begin to appear in the

patterns when $\mathrm{Al}(\mathrm{acac})_{3}$ was mixed with $\mathrm{Fe}(\mathrm{acac})_{3}$ at different percentages (w/w \%): $1 \%$ (a), $5 \%$ (b), and $10 \%$ (c)

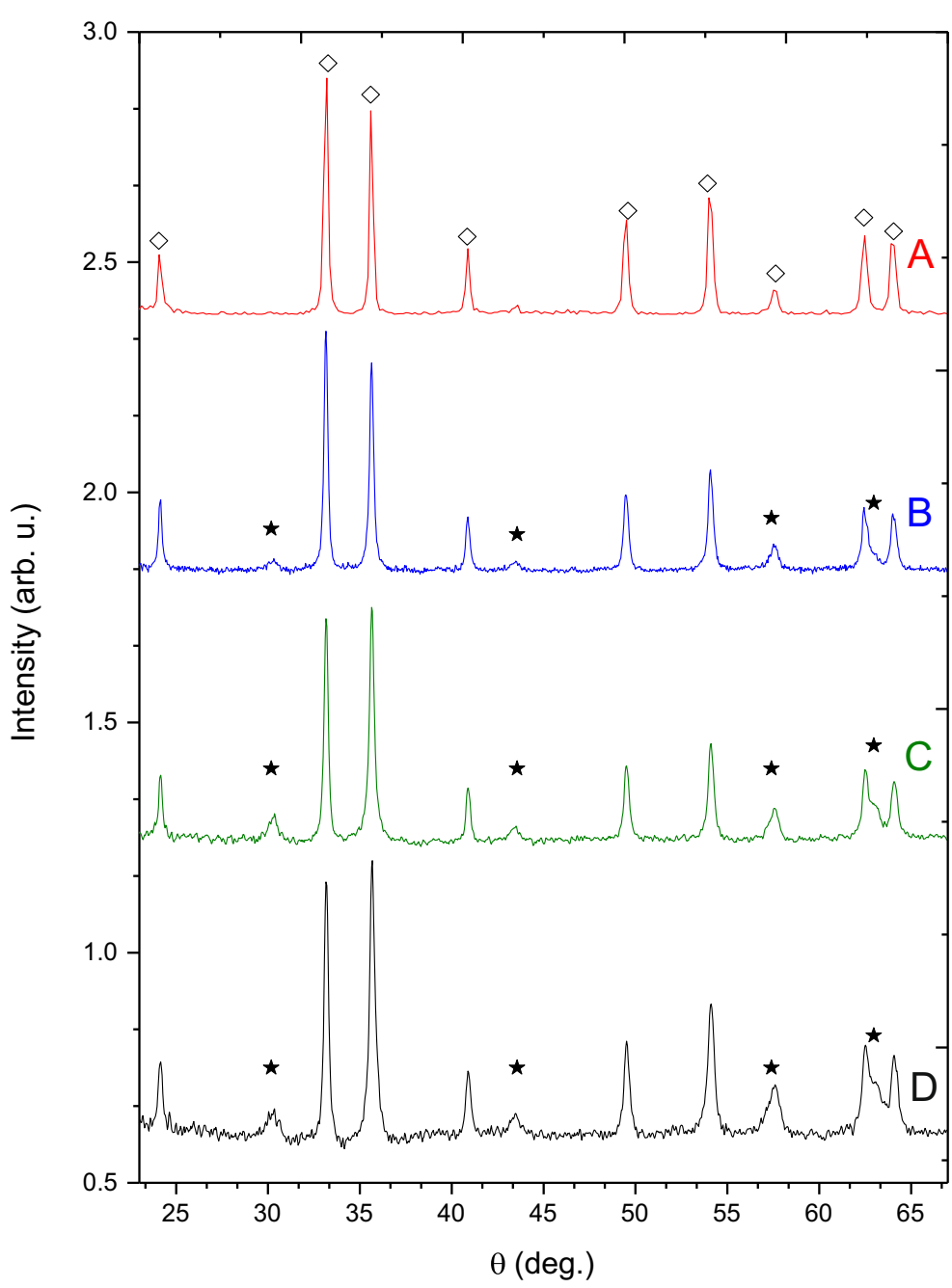

Table 1 Summary of precursor mixture compositions

\begin{tabular}{|c|c|c|c|}
\hline $\begin{array}{l}\text { Precursor } \\
\text { mixture }\end{array}$ & $\begin{array}{l}\text { Composition } \\
\mathrm{Al}(\mathrm{acac})_{3}: \\
\mathrm{Fe}(\mathrm{acac})_{3} \\
(w / w) \%^{\mathrm{a}}\end{array}$ & $\begin{array}{l}\text { Theoretical } \\
\text { composition } \\
\mathrm{A} 1 / \mathrm{Fe} \\
(w / w \%)^{\mathrm{b}}\end{array}$ & $\begin{array}{l}\text { Experimental } \\
\text { composition } \\
\mathrm{Al} / \mathrm{Fe} \\
(w / w \pm \alpha \%)^{\mathrm{c}}\end{array}$ \\
\hline A & 0 & 0 & n.d. \\
\hline B & 1 & 0.53 & $0.65 \pm 0.5$ \\
\hline $\mathrm{C}$ & 5 & 2.76 & $2.78 \pm 0.3$ \\
\hline D & 10 & 5.84 & $5.61 \pm 0.6$ \\
\hline
\end{tabular}

${ }^{a}$ Precursor mixtures were obtained by mixing $\mathrm{Al}(\mathrm{acac})_{3}$ and $\mathrm{Fe}(\mathrm{acac})_{3}$ in different mass ratios $(0,1,5$, and $10 \%)$

${ }^{\mathrm{b}}$ The theoretical $\mathrm{Al} / \mathrm{Fe}$ mass ratio was calculated considering $\mathrm{Al}(\mathrm{acac})_{3} / \mathrm{Fe}(\mathrm{acac})_{3}$ mass ratio

${ }^{\mathrm{c}}$ Spectrophotometry was employed to determine the $\mathrm{Al} / \mathrm{Fe}$ mass ratio into the final product (oxide)

n.d. not detected addition of concentrated $\mathrm{H}_{2} \mathrm{O}_{2}$ became compulsory in order to precisely quantify the real amount of iron in the samples, as the photometric method is specific solely for $\mathrm{Fe}^{3+}$. As a matter of fact, a good match between the theoretical and the real Al-content in the oxide should depend just on the purity of the starting reagents provided that external contamination sources are minimized.

Porous hematite layers showed a rough surface (Fig. 2a) without any crack or hole. The roughness (RMS) was calculated by confocal microscopy and was in the range 960-850 nm. The film thickness was also determined through confocal topographical analysis (Fig. 2b). The average thickness of porous layers was $4.2 \pm 0.5 \mu \mathrm{m}(n=3)$. Such morphology was obtained after firing the paste since all organic components are burned out leaving empty spaces between sintered nanoparticles. From microscopy images, we also can notice a 

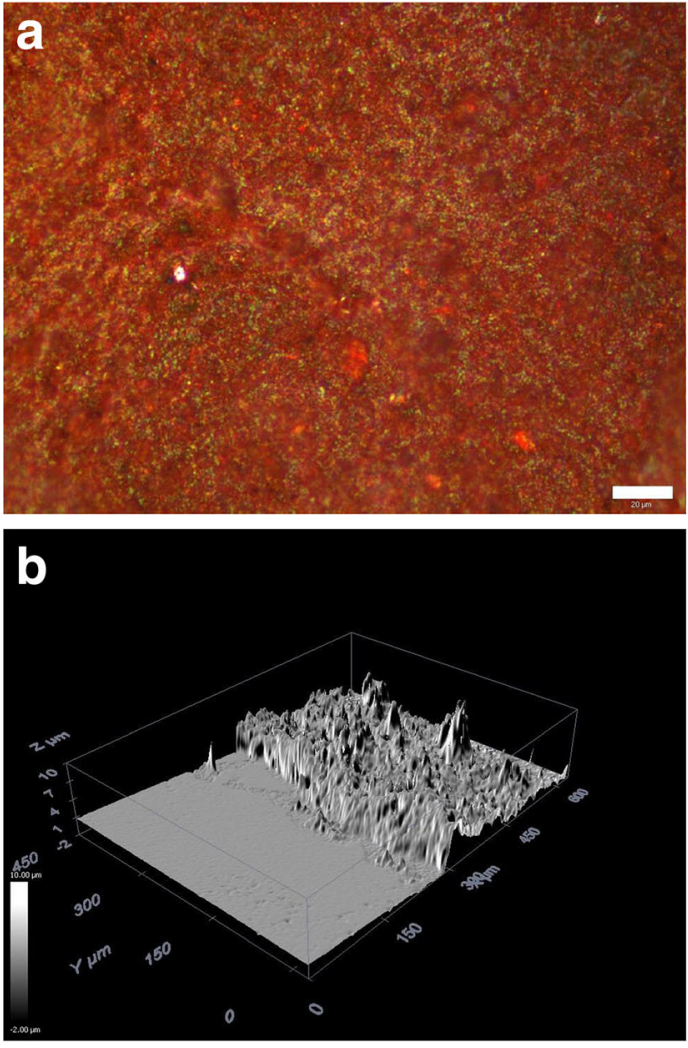

Fig. 2 Confocal microscopy images of the surface of $\mathrm{Fe}_{2} \mathrm{O}_{3}$ photoanodes: a true color micrograph of the surface with $20 \times$ magnification (a), the size of the white bar was $2 \mu \mathrm{m}$; 3D topography of a border region of the electrode (b), the FTO substrate

macroporous ${ }^{1}$ structure of surface. Notice that a porous surface is preferred in DSSC due to the higher surface area, higher dye loading, and the easier penetration and diffusion of the electrolyte (during the operation of the device). In addition to that, the presence of macropores offers the possibility to explore other redox mediators with larger structure such as cobalt (II/III) bipyridine shuttles. In fact, redox mediators consisting of big organometallic complexes possess low diffusion coefficient and large pores generally facilitate their diffusion through the cells (Heo et al. 2012; Trang pham et al. 2014). As shown in Fig. 2c, a higher magnification of the surface, presents pores with a size in the range $10-30 \mu \mathrm{m}$.

Atomic force microscopy has been performed on solid film samples in order to obtain morphological information such as nanoparticle shape and size. Figure 3 represents two different nanoparticle films, obtained by firing different precursor mixtures.

\footnotetext{
${ }^{1}$ Pores had a linear size larger than $50 \mathrm{~nm}$.
}

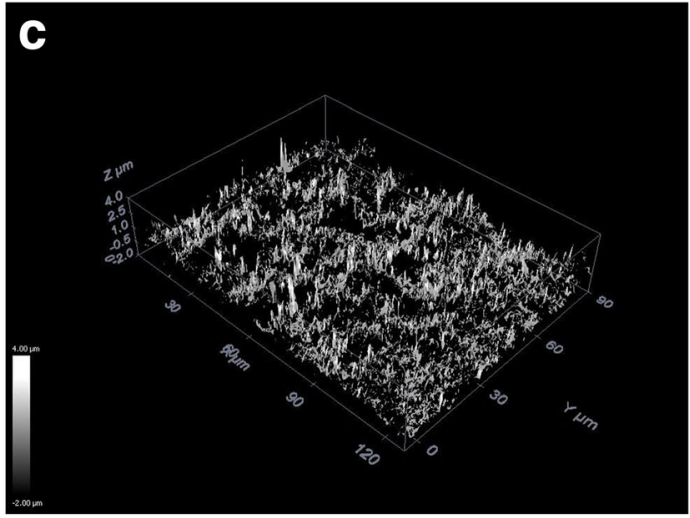

appears as a flat region; 3D topography of a central region of the porous film using $100 \times$ magnification $(\mathbf{c})$, the pores appear as black holes on the surface

As shown in Fig. 3a, the step of thermal degradation of pure $\mathrm{Fe}(\mathrm{acac})_{3}$ (mixture A) leads to the formation of round hematite nanoparticles with an average radius of $54 \pm 16 \mathrm{~nm}$ (the average is determined from $100 \mathrm{sam}$ ples). Equation 1 describes the degradation (combustion) reaction between the precursor and oxygen.

$$
\begin{aligned}
& 4 \mathrm{Fe}\left(\mathrm{C}_{5} \mathrm{H}_{7} \mathrm{O}_{2}\right)_{3(\mathrm{~s})}+72 \mathrm{O}_{2(\mathrm{~g})} \rightarrow 2 \mathrm{Fe}_{2} \mathrm{O}_{3(\mathrm{~s})} \\
& +42 \mathrm{H}_{2} \mathrm{O}_{(\mathrm{g})}+60 \mathrm{CO}_{2}(\mathrm{~g})
\end{aligned}
$$

As confirmed by XRD (Fig. 1a), the oxide obtained by firing mixture $\mathrm{A}$ has shown just the hematite $(\alpha-$ $\mathrm{Fe}_{2} \mathrm{O}_{3}$ ) crystal phase. Thermal treatment of the paste containing Al leads to the formation of Al-doped nanoparticles. As shown in Fig. 3b, the morphology of the film obtained using mixture D presented smaller nanoparticles $(25 \pm 5 \mathrm{~nm})$. Al-containing nanoparticles appear to be more compact and form relatively large blocks with some cracks. 
Fig. 3 AFM image of the surface of a thin layer of $\mathrm{Fe}_{2} \mathrm{O}_{3}$ nanoparticles, obtained by thermal degradation of pure $\mathrm{Fe}(\mathrm{acac})_{3}$ on FTO (a). The image b represents the morphology of the films obtained using mixture D a

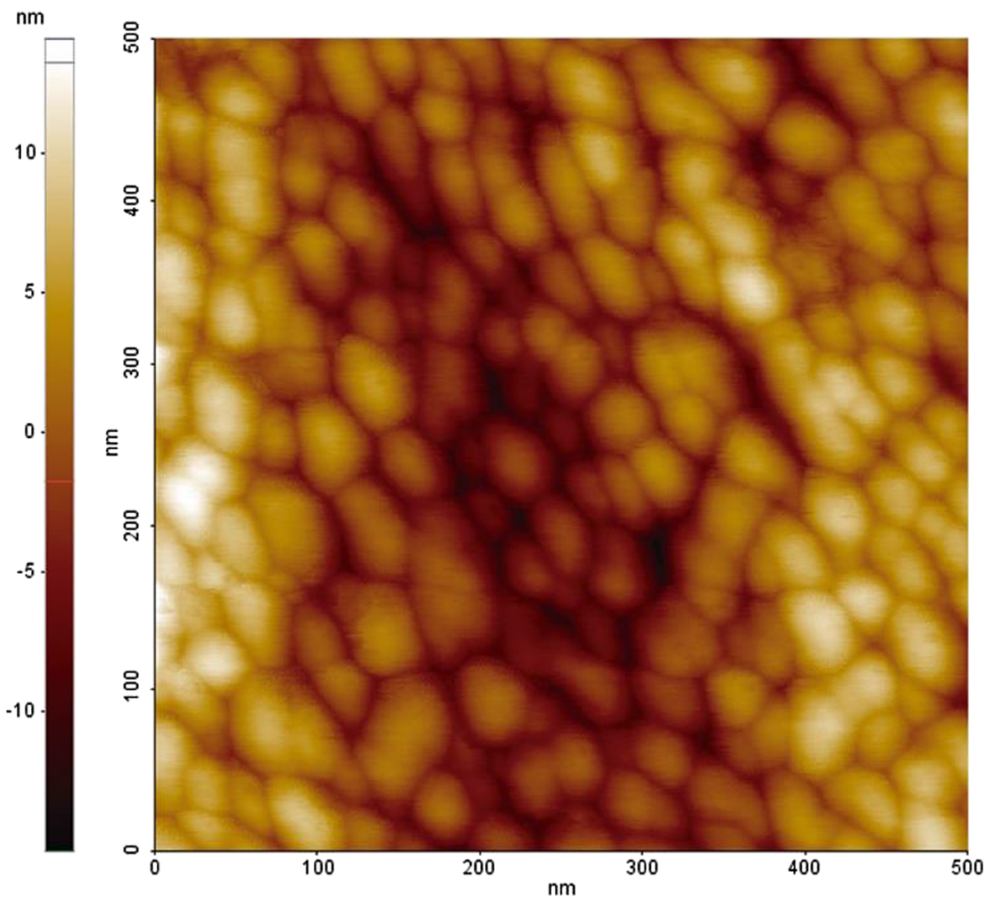

b

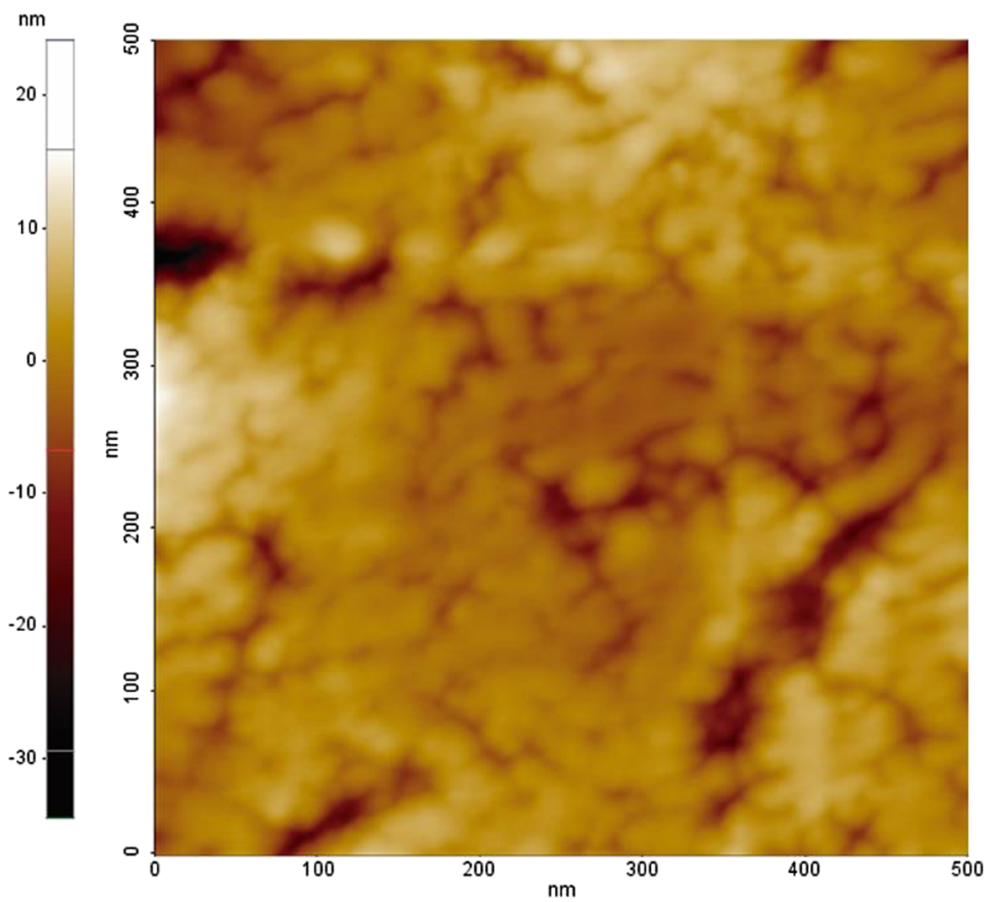

Sensitized electrodes were characterized as photoanodes of DSSCs under simulated sun light (AM
1.5, 1 sun) using platinized FTO as CE. In Fig. 4, the current/voltage responses of three different hematite- 
based DSSCs are represented. The first cell setup (A) consists of a porous layer of hematite, obtained with the method described in the previous section. In order to determine the photovoltaic efficiency of the sole hematite, in one configuration, no sensitization was considered. The second and third configurations consist of, respectively, a porous hematite film sensitized with N3 (B) and D5 (C): in these configurations, electrodes were dipped into the dye solution for $8 \mathrm{~h}$.

Under simulated sun light, all photoanodes have produced expectedly anodic photocurrents. In absence of sensitization, pure hematite produced low photocurrent and a photovoltage. As expected, the efficiency of the cell with no dye was the lowest of the sample set. The absorption of organometallic dye N3 on the hematite anodes surface leads to a significant increase of the PV performance. However, better performance has been obtained with D5 dye which has shown the largest PV parameters within this set of samples. In order to improve the cell efficiency, the dyeing time was extended to $16 \mathrm{~h}$, and the measurements were performed in the same experimental conditions (Fig. 4). All results are summarized in Table 2. By prolonging the dipping time, we noticed a significant increase in the photocurrent densities of both D5- and N3-sensitized hematite photoanodes. The gain in photocurrent density was about $20 \%$ of the values obtained from the films dipped for $8 \mathrm{~h}$ in the dyeing solution. This is probably due to a similar diffusion coefficient of the dyes inside the porous $\mathrm{Fe}_{2} \mathrm{O}_{3}$ layer. A longer dyeing time increases the quantity of absorbed dye in the active sites of the mesoporous oxide. Thus, a higher quantity of electrons is injected into the conduction band of hematite generating a higher photocurrent. As shown in Table 2, for D5, we noticed an improvement of the FF and the efficiency of the cell sensitized for $16 \mathrm{~h}$. Probably, the higher quantity of absorbed dye influences the overall electron injection efficiency at the photoanode surface. This is also confirmed by a significant improvement of the cell efficiency (about $30 \%$ higher). Also, with N3 dye sensitizer, we have observed an enhancement of the PV characteristics of DSSCs upon prolongation of the dyeing time. In fact, the cell efficiency showed an increase of about $20 \%$.

The measurements were performed under simulated sunlight AM 1.5 (1 sun)

\section{Doping with different percentages of $\mathrm{Al}$}

The isovalent substitution of $\mathrm{Fe}^{3+}$ with $\mathrm{Al}^{3+}$ was considered in order to increase both band gap and charge carrier concentration of the semiconductor. The replacement of $\mathrm{Fe}^{3+}$ with $\mathrm{Al}^{3+}$ ions in the mixed oxide was performed by using different mixtures of acetylacetonate complexes of the two metals. The changes in optical absorption were registered on samples made of thin layers of nanoparticles deposited onto FTO with percentages of $\mathrm{Al}(\mathrm{acac})_{3}$ varying from 0 to $10 \%$. The UVVis absorption spectra of the various samples are represented in Fig. 5.
Fig. 4 Current vs voltage response of hematite-based dye solar cells. A pure layer of porous hematite (black triangle) with no absorbed dye was used for comparison. Porous hematite layers were sensitized with $\mathrm{N} 3$ for 8 (black star) and $16 \mathrm{~h}$ (white star). Also, the dyeing with the organic D5 was considered for 8 (white square) and $16 \mathrm{~h}$ (white circle). The measurements were performed on sealed cells using HSE bv12 iodine-based electrolyte under the light of a sun simulator (AM 1.5; 1 sun)

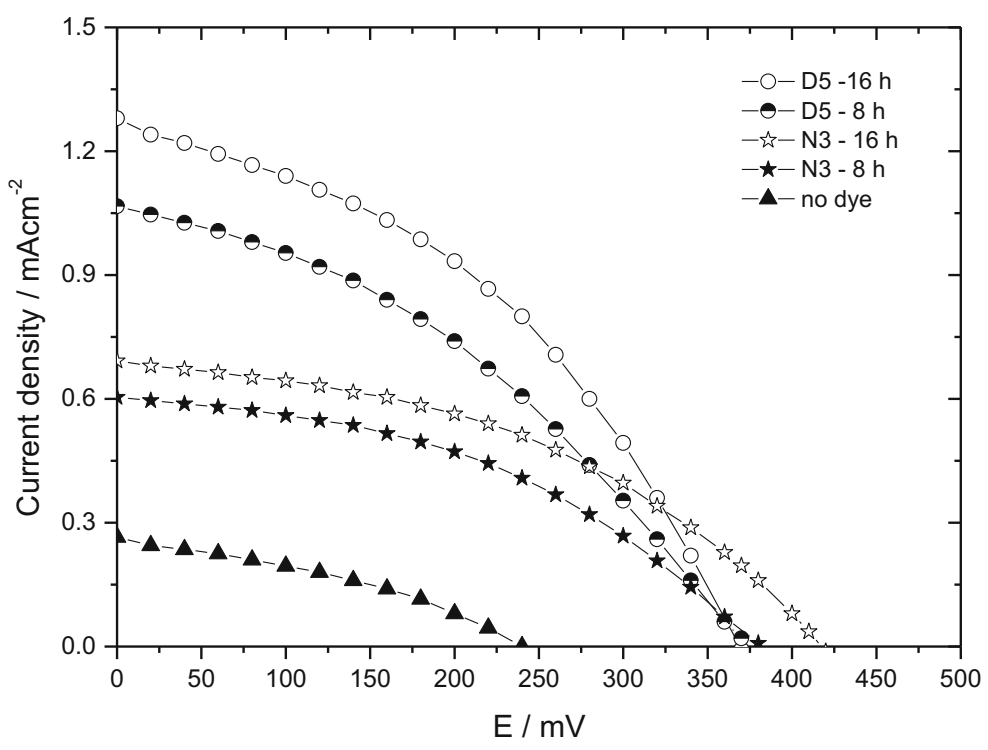


Table 2 Summary of the PV parameters of different solar cells based on two different photoelectrodes: hematite photoanodes ( $n$-type) and, for comparison, $\mathrm{NiO}$ ( $p$-type) sensitized with erythrosine (EryB) and P1

\begin{tabular}{|c|c|c|c|c|c|c|c|c|}
\hline Material & DSSC type (n/p) & Dye & Dipping time (h) & $\mathrm{Jsc}\left(\mathrm{mAcm}^{-2}\right)$ & $\operatorname{Voc}(\mathrm{V})$ & $\mathrm{FF}(\%)$ & Eff $(\%)$ & Reference \\
\hline $\mathrm{TiO}_{2}$ & $\mathrm{n}$ & D5 & 16 & 11.040 & 0.619 & 58.0 & 3.99 & (DESSI et al., 2014) \\
\hline $\mathrm{TiO}_{2}$ & $\mathrm{n}$ & N3 & 16 & 19.220 & 0.720 & 67.4 & 9.33 & (ADACHI et al., 2004) \\
\hline Hematite & $\mathrm{n}$ & D5 & 16 & 1.280 & 0.370 & 41.8 & 0.198 & this work \\
\hline Hematite & $\mathrm{n}$ & N3 & 16 & 0.692 & 0.418 & 42.2 & 0.122 & this work \\
\hline Hematite & $\mathrm{n}$ & D5 & 8 & 1.060 & 0.370 & 37.4 & 0.147 & this work \\
\hline Hematite & $\mathrm{n}$ & N3 & 8 & 0.604 & 0.380 & 42.7 & 0.098 & this work \\
\hline Hematite & $\mathrm{n}$ & - & - & 0.265 & 0.240 & 35.0 & 0.022 & this work \\
\hline Hematite & $\mathrm{n}$ & $\begin{array}{l}\text { Ruthenizer } \\
\text { 535-bisTBA }\end{array}$ & 12 & 0.250 & 0.420 & 38.0 & 0.04 & $\begin{array}{r}\text { (Rashid; Kishi; } \\
\text { Soga, 2016) }\end{array}$ \\
\hline $\mathrm{NiO}$ & $\mathrm{p}$ & EryB & 24 & -0.412 & -0.125 & 35.8 & 0.022 & (Novelli et al., 2015) \\
\hline $\mathrm{NiO}$ & $\mathrm{p}$ & SQ2 & 7 & -0.693 & -0.132 & 37.6 & 0.041 & (Novelli et al., 2015) \\
\hline $\mathrm{NiO}$ & $\mathrm{p}$ & $\mathrm{P} 1$ & 16 & -2.84 & -0.125 & 33.7 & 0.121 & (Gibson et al., 2013) \\
\hline
\end{tabular}

The determination of the direct band gap $\left(E_{\mathrm{g}}\right)$ of the films was accomplished through Tauc plots utilizing the UV-Vis spectra of the films. Pure $\alpha-\mathrm{Fe}_{2} \mathrm{O}_{3}$ thin films exhibited an $E_{\mathrm{g}}$ of $2.1 \mathrm{eV}$, a value characteristic of hematite (Shinde et al. 2011; Tamirat et al. 2016). Films obtained by firing mixture $\mathrm{B}\left(1 \% \mathrm{Al}(\mathrm{acac})_{3}\right)$ had shown a slight decrease of $E_{\mathrm{g}}(2.05 \mathrm{eV})$. Also, mixture C, which contains $5 \%$ of $\mathrm{Al}(\mathrm{acac})_{3}$, led to the formation of films with a lower $E_{\mathrm{g}}(1.86 \mathrm{eV})$. Mixture D ( $10 \%$ of $\left.\mathrm{Al}(\mathrm{acac})_{3}\right)$ gave a film presenting a sharp increase of $E_{\mathrm{g}}$ $(2.45 \mathrm{eV})$. Such an effect is also accompanied by the blue shift of the main absorption band in the respective UV-Vis spectrum (Fig. 5). For further information about $E_{\mathrm{g}}$ data and measurements, please refer to S.I. In Fig. 6, one can see that mixture D formed films with a lower absorbance in the region 340-600 $\mathrm{nm}$. Contrariwise, films obtained using mixture $\mathrm{C}$ presented a broad peak in the region 575-700 $\mathrm{nm}$.

With the same method reported in the experimental section, Al-doped nanoparticles have been obtained and used to prepare dense and spreadable pastes. Al-doped hematite photoanodes have been deposited and sintered
Fig. 5 Absorbance spectra of thin layers of Al-doped $\mathrm{Fe}_{2} \mathrm{O}_{3}$ on FTO. Different concentration ratios $(w / w)$ of $\mathrm{Al}(\mathrm{acac})_{3}$ were used in precursor mixtures $\mathrm{A}, \mathrm{B}, \mathrm{C}$, and D: 0 (black triangle), 1 (black star), 5 (white circle), and $10 \%$ (white star). In order to obtain a quasi-transparent film, only $10 \mathrm{mg}$ of the precursor mixtures were dissolved in $1 \mathrm{~mL}$ water/ ethanol $(50 / 50 v / v)$ and were deposited on clean FTO at the dosage $100 \mu \mathrm{L} \mathrm{cm}^{-2}$, and then fired

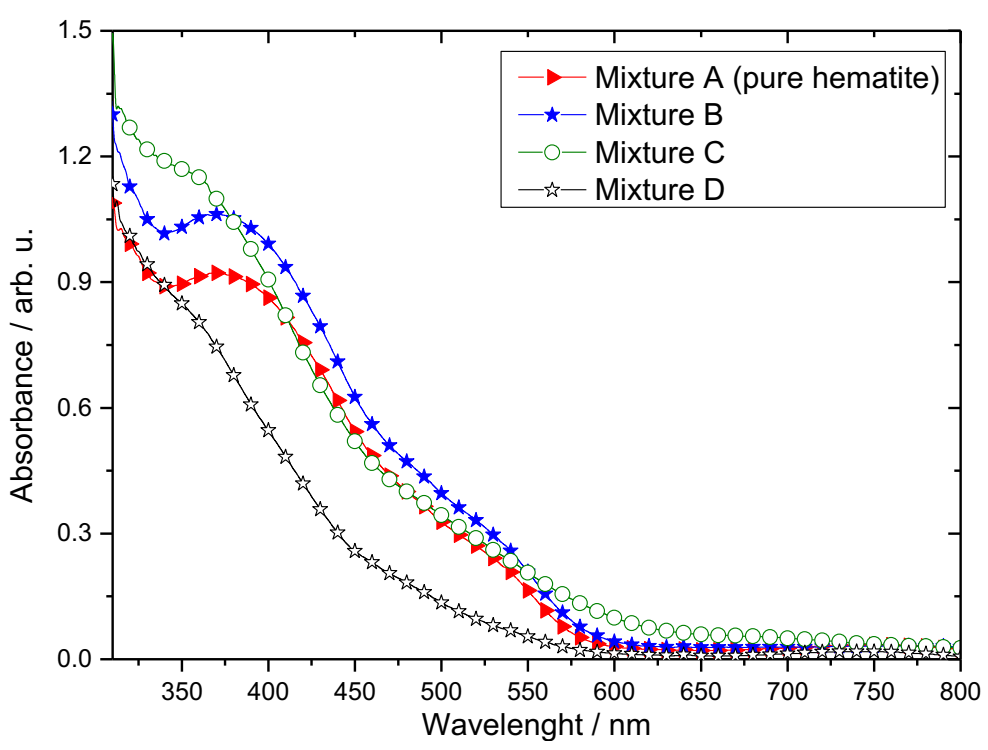


Fig. 6 JV curves of D5sensitized photoanodes fabricated using different percentages of $\mathrm{Al}(\mathrm{acac})_{3}$ in the precursor mixtures: mixture A: 0\% (black triangle); mixture $\mathrm{B}: 1 \%$ (white square); mixture C: $5 \%$ (white circle); mixture D: $10 \%$ (black square). JV measurements were performed under simulated sun light AM 1.5 (1 sun)

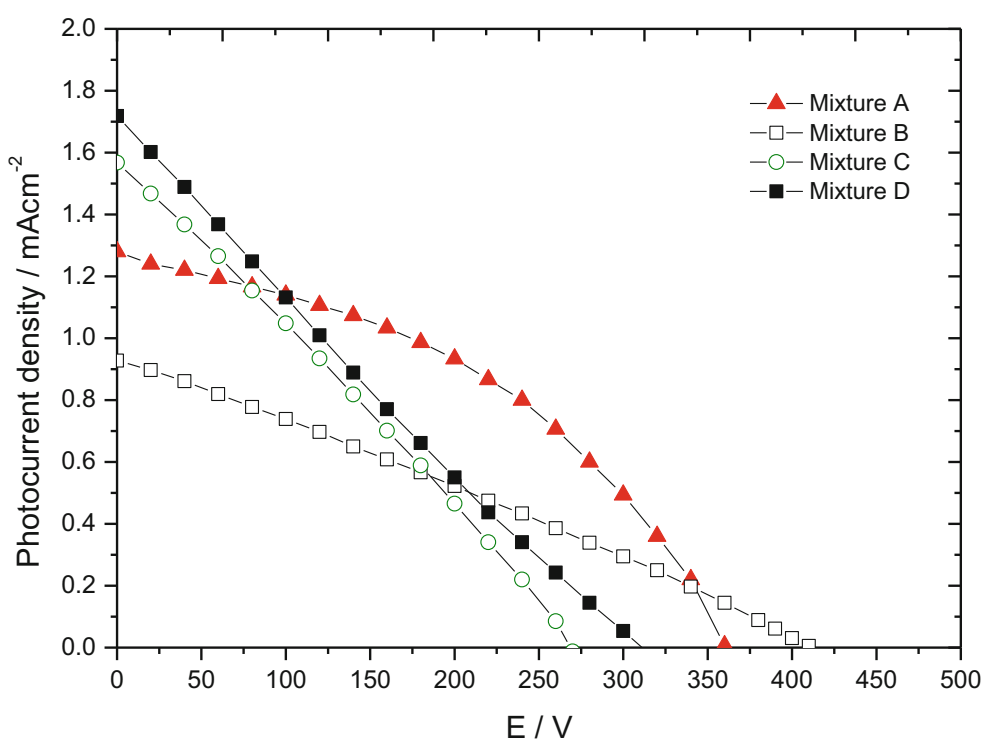

following the same procedure used for pure hematite. The obtained photoanodes have been characterized using only D5 as sensitizer, due to its higher performance with hematite (Fig. 4, vide supra). The PV parameters of the sensitized photoanodes are listed in Table 3, which reports also the compositions of the respective precursor mixtures.

From Table 3, it resulted in the increase of $J_{\text {sc }}$ as a function of Al-content in the precursor mixture (Tables 1 and 3, second column). This effect can be explained considering the effect of Al-doping, on hematite's electronic properties. In fact, it was reported by KleimanShwarsctein et al. in 2010 that the charge carrier density was in the range of $4-7 \times 10^{21} \mathrm{~cm}^{-3}$ for pure electrodeposited hematite and $1.3 \times 10^{22} \mathrm{~cm}^{-3}$ for the Al-doped sample (Kleiman-Shwarsctein et al. 2010). In their experiments, Kleiman-Shwarsctein used a percentage of $\mathrm{Al}$ of $10 \%$. This effect on the charge carrier density was also reported by Shinde et al. in 2011, in sputtered Al-doped hematite films (SHINDE et al. 2011). In the experiment described in this work, the increase of the $\mathrm{Al} / \mathrm{Fe}$ mass ratio (from 0 to $5.61 \%$ ) leads to sensible reduction of $V_{\mathrm{oc}}$ and of FF. As a result, lower efficiencies were obtained when mixtures B, C, and D were used to prepare Al-doped nanoparticles (Fig. 6 and Table 3). As confirmed from EIS spectra (Fig. 7), Al-doped hematite showed a lower charge transfer resistance. This renders the recombination of the injected electron with the electrolyte more favorable instead of its diffusion to the external contact. The higher recombination rate of electrons at the electrolyte/ photoanode interface influences negatively the fill factor of the cell. In fact, as shown by $J V$ plots (Fig. 6), the higher the $\mathrm{Al}$ content the higher the slope of the curve and the lower the FF. Using photoanodes prepared with the mixture D, the corresponding cell gave $J_{\mathrm{sc}}=1.720 \mathrm{mAcm}^{-2}$, i.e., $25 \%$ higher than that obtained using pure hematite (mixture A, Table 3). Photoanodes prepared with the mixture $\mathrm{C}$ gave cells that produced an increase of about $18 \%$ in efficiency with respect to undoped photoanodes. With mixture B, the corresponding photoanode produced a cell with the highest value of open circuit photovoltage within this set of $n$-DSSCs $\left(V_{\mathrm{oc}}=410 \mathrm{mV}\right)$. Mixture A (pure hematite) showed a good value of $J_{\mathrm{sc}}$. Moreover, the shape of the curve was characterized by a higher FF (41.8\%) and a higher efficiency $(0.198 \%)$. Despite the lower performance obtained with mixture $\mathrm{D}$, there was a significant gain in the device transparency. In fact, from the transmittance values of the photoanodes, one can notice that the semi-transparency of the electrode is obtained using just $10 \% \mathrm{Al}(\mathrm{acac})_{3}$ in the precursor mixture (Table 4). The lower absorbance of the photoanode, in a tandem DSSC illuminated from both sides, results in a higher quantity of solar radiation reaching the photocathode.

As a result of the $J V$ characterization, the doping with Al led to a poorer PV performance in all values of concentrations here considered. In order to understand the effect of $\mathrm{AlFe}_{2} \mathrm{O}_{4}$ on the photoanode's electrochemistry, EIS measurements (Fig. 7) have been performed on the devices. The spectra were registered in forward 
Table 3 PV parameters of different solar cells based on hematite photoanodes prepared using different weight percentages $(w / w)$ of $\mathrm{Al}$ $(\mathrm{acac})_{3}$ in the precursor mixture

\begin{tabular}{|c|c|c|c|c|c|c|c|c|}
\hline Mixture $^{\mathrm{a}}$ & $\mathrm{Al}(\mathrm{acac})_{3}$ & $\mathrm{Al}: \mathrm{Fe}(\mathrm{w}: \mathrm{w} \%)$ & Dye & $J_{\mathrm{sc}}\left(\mathrm{mAcm}^{-2}\right)$ & $\operatorname{Voc}(\mathrm{V})$ & $\mathrm{FF}(\%)$ & $\eta(\%)$ & $T_{500}^{\mathrm{b}}(\%)$ \\
\hline $\mathrm{D}$ & $10 \%$ & $5.61 \pm 0.6$ & D5 & 1.720 & 0.310 & 23.6 & 0.126 & 70 \\
\hline $\mathrm{C}$ & $5 \%$ & $2.78 \pm 0.3$ & D5 & 1.560 & 0.260 & 28.0 & 0.113 & 3 \\
\hline B & $1 \%$ & $0.65 \pm 0.5$ & D5 & 0.613 & 0.410 & 27.9 & 0.105 & 0 \\
\hline A & 0 & nd & D5 & 1280 & 0.370 & 41.8 & 0.198 & 0 \\
\hline
\end{tabular}

bias (n-type), applying $V_{\text {oc }}$ (negative voltages) as external bias. Notice that, in the EIS setup, the photoanode is the working electrode and Pt is both the counter and the reference electrode. So, all of the applied voltages are considered vs Pt. The negative voltages are required for the forward bias configuration, because hematite is an $n$ type semiconductor. For further information about the $n$ type behavior of Al-doped hematite photoanodes, please see S.I. (Mott-Schottky plots). EIS spectra have been fitted in order to extract the key parameters involved in the charge-transfer process. Notice that the charge transfer at the interface dye/electrolyte is an adverse reaction in the whole functioning of the device. In fact, the charge transferred back to the electrolyte does not contribute to the photocurrent nor to the photovoltage. The sole charges which generate the current in the external circuit are those which are conducted from the surface of the semiconductor to the FTO. In a typical DSSC, one can distinguish two separate sides where recombination takes place: the $\mathrm{CE}$ and the photoanode (PA) or photocathode (PC). In this respect, DSSC can be considered as an electronic circuit (equivalent circuit) in which each element (resistor, capacitor, etc.) is associated to a specific process. The inset in Fig. 7 represents the equivalent circuit used for the analysis of both $p$ DSSC and $n$-DSSC (BONOMO et al. 2016). The circuit consists of the following: (i) a series resistance, which takes account to the charge transport through the external circuit $\left(R_{\mathrm{S}}\right)$; (ii) the resistance term $R_{\mathrm{CE}}$ in parallel with the capacitive term CPE, e.g., the constant phase element, representative of the recombination at the $\mathrm{CE} /$ electrolyte interface; (iii) a transmission line element modeling the behavior of the porous oxide films (e.g., $\mathrm{NiO}$ and $\mathrm{Al}$-doped hematite) at the interface with the electrolyte, which also considers the internal charge transport through the nanoparticles.

Some key parameters related to the charge transport properties of the oxide films can be directly obtained by fitting: the most important ones are the charge transport resistance $\left(R_{\mathrm{t}}\right)$ through the
Fig. 7 Nyquist plot of two complete $n$-type DSSCs using D5 as photosensitizer, absorbed on porous hematite layers of nanoparticles obtained by mixture A (black square) and mixture D (circle with upper half black). The analysis was performed in the dark applying the respective $V_{\text {oc }}$ as forward bias. The forward bias polarization forces the electrons to recombine with the electrolyte simulating the recombination in operational conditions. The inset shows the equivalent circuit (transmission line) used to fit the experimental data and extract the key parameters fundamental for the comparative analysis

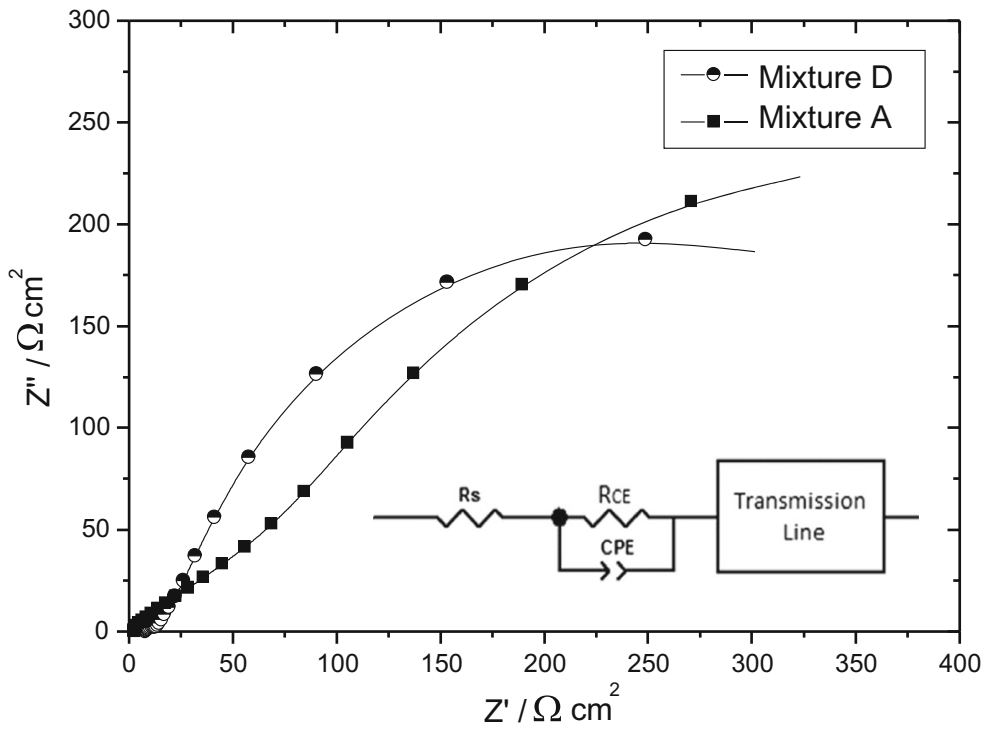


Table 4 Key transport parameter, calculated by fitting the experimental data with the equivalent circuit represented in Fig. 7

\begin{tabular}{llllll}
\hline Photoelectrode & Type & Dye & $R_{\mathrm{t}} / \Omega \mathrm{cm}^{2}$ & $R_{\text {rec }}\left(\Omega \mathrm{cm}^{2}\right)$ & $C_{\mu} / \mu \mathrm{F}$ \\
\hline NiO & $p$ & ERY & $27.5 \pm 0.5$ & $521.8 \pm 2.5$ & $439 \pm 3$ \\
Pure hematite (mixture A) & $n$ & D5 & $50.4 \pm 3.7$ & $817.6 \pm 49.5$ & $693 \pm 14$ \\
Hercynite/hematite (mixture D) & $n$ & D5 & $13.7 \pm 0.4$ & $449.0 \pm 5.9$ & $803 \pm 11$ \\
\hline
\end{tabular}

nanoparticles of the oxide films and the charge transfer resistance $\left(R_{\text {rec }}\right)$ through PA (or PC) and electrolyte. Furthermore, the chemical capacitance $C_{\mu}$ included in the transmission line (Fig. 7) can be deducted by means of the fitted value of CPE through the relationship $C_{\mu}=\left(C_{\mathrm{CPE}} * R_{\mathrm{rec}}\right)^{1 / n} / R_{\text {rec }}$ where $C_{\mathrm{CPE}}$ and $n$ are used as fitting parameters (FabregatSantiago et al. 2011; Hirschorn et al. 2010). Other important parameters directly correlated to the terms presented above are (i) the hole (or electron) diffusion time $\tau_{\mathrm{d}}\left(=R_{\mathrm{t} *} C_{\mu}\right)$, which represents the time spent by the photoinjected charge carrier to cross the semiconducting layer, and (ii) the recombination time $\tau_{\mathrm{h}}$ $\left(=R_{\text {rec }} C_{\mu}\right)$, e.g., the lifetime of the photoinjected charge before it undergoes recombination. As far as the CE of the DSSC is concerned, its characterization and performance evaluation rely on the determination of the term $R_{\mathrm{CE}}$, e.g., the charge transfer resistance at the CE/electrolyte interface, and of the term CPE describing the capacitance of the double layer generated at the same interface.

The values represent the charge transfer kinetic at the interface photoelectrode/electrolyte. In the transmission line model, the term $R_{\mathrm{t}}$ takes in account the internal resistance of the porous oxide films. The charge recombination at the interface with the electrolyte is represented by two values: the recombination resistance $\left(R_{\text {rec }}\right)$ and the double layer capacitance $C_{\mu}$

As shown in Table 4, Al doping modifies the charge transport properties of the porous oxide film. In fact, one can see a significant reduction of the term $R_{\mathrm{t}}$ which changes from $50.4 \pm 3.7$ to $13.7 \pm 0.4 \Omega \mathrm{cm}^{2}$ upon addition of $10 \% \mathrm{Al}(\mathrm{acac})_{3}$ to the precursor mixture. This effect can be explained with the increase of conductivity from $3.58 \times 10^{-2}$ for pure hematite to $3.70 \times 10^{-2}$ $(\Omega \mathrm{m})^{-1}$ for $10 \%$ Al-doped films, as observed also by Shinde et al. (2011). Notice that $10 \%$ of $\mathrm{Al}(\mathrm{acac})_{3}$ does not mean $10 \%$ of $\mathrm{Al}$ in the final product (Table 1). Another effect of the presence of $\mathrm{Al}$ into the hematite films is the reduction of the $R_{\text {rec }}$ which makes the recombination more favorable. For this reason, when an Al-doped electrode was used as photoanode, the respective $J V$ curves show a higher slope in comparison with those obtained using pure hematite. This effect affects directly the FF of the cell and thus the overall efficiency. However, when $\mathrm{Al}(\mathrm{acac})_{3}$ is mixed at $10 \%$ $(w / w)$ with $\mathrm{Fe}(\mathrm{acac})_{3}$, a transparent electrode was obtained (mixture D, Fig. 5). So, this concentration could be considered in order to produce an optically performing photoactive "counter electrode" for a tandem $p$-DSSC. In fact, as shown in Table 3, this photoanode, sensitized with D5, produces photocurrents compliant with that of a typical $p$-DSSC based on $\mathrm{NiO}$ sensitized with ERY.

\section{Conclusions}

A print-compatible method, based on non-expensive chemical precursors, was here proposed for the deposition of $n$-type nanoparticles of pure hematite and its Aldoped versions on conductive FTO. The proposed method consists of the thermal degradation of a precursor mixture, which allows the easy and non-expensive fabrication of sintered photoanodes. The inclusion of aluminum into the precursor mixture leads to a mixed phase hematite/hercynite with different optical and electrochemical characteristics. The as-deposited layers were dyed with N3 and D5 sensitizers, two dyes commonly employed in DSSCs based on $\mathrm{TiO}_{2}$ mesoporous photoanodes. In working conditions, the photoanodes sensitized with D5 (organic) resulted more efficient than those sensitized with N3 (organometallic). For this reason, D5 was further considered for a more in-depth electrochemical characterization in order to understand the effect of the presence of $\mathrm{Al}^{3+}$ on the cell's performance. As a result, pure hematite showed higher PV performance in comparison with Al-doped photoanodes. A significant enhancement in the photocurrent was obtained using the photoanode with $5.61 \% \mathrm{Al} / \mathrm{Fe}(w / w)$. In addition to that, this concentration makes the electrode semi-transparent ( $T \%=70 \%$ at $500 \mathrm{~nm}$ ). With $0.65 \%$ 
$\mathrm{Al} / \mathrm{Fe}(w / w)$, the cell showed a gain in photovoltage, although the drop in the fill factor leads to a lower efficiency in comparison to that of pure hematite. One of the most important findings of this work is the evidence of a similar recombination kinetics concerning the charge transfers at $\mathrm{NiO} / \mathrm{ERY} / \mathrm{electrolyte}$ and hematite/ D5/electrolyte interfaces. Moreover, the photocurrent value compliance makes this electrode particularly interesting in a tandem cell configuration using ERYsensitized $\mathrm{NiO}$ photocathodes. For example, a sandwich of hematite layers doped with increasing concentrations of Al, deposited on pure hematite, could be exploited for combining all advantages in terms of transparency, photovoltage, and photocurrent. The $\mathrm{Al} / \mathrm{Fe}$ ratio should be studied in the range $0-1 \%$ in order to optimize the photovoltage in a future study on complete tandem devices.

Acknowledgments We especially thank Mr. Luiz Meneghetti Jr. for the technical support.

\section{Compliance of ethical standards}

Conflict of interest The authors declare that they have no conflict of interest.

\section{References}

Adachi M et al (2004) Highly efficient dye-sensitized solar cells with a titania thin-film electrode composed of a network structure of single-crystal-like $\mathrm{TiO} 2$ nanowires made by the "oriented attachment" mechanism. J Am Chem Soc 126(45): 14943-14949

Awais M et al (2011) Application of a novel microwave plasma treatment for the sintering of nickel oxide coatings for use in dye-sensitized solar cells. Surf Coat Technol 205:S245-S249

Bonomo $\mathrm{M}$ et al (2016) Beneficial effect of electron-withdrawing groups on the sensitizing action of Squaraines for p-type dyesensitized solar cells. J Phys Chem C 120(30):16340-16353

Bonomo M, Dini D (2016a) Nanostructured p -type semiconductor electrodes and Photoelectrochemistry of their reduction processes. Energies 9(1):373

Bonomo M, Dini D (2016b) Nanostructured p-type semiconductor electrodes and Photoelectrochemistry of their reduction processes. Energies 9(5):373

Congiu M et al (2015a) Single precursor route to efficient cobalt sulphide counter electrodes for dye sensitized solar cells. Electrochim Acta 151(0):517-524

Congiu $\mathrm{M}$ et al (2015b) A novel and large area suitable waterbased ink for the deposition of cobalt sulfide films for solar energy conversion with iodine-free electrolytes. Sol Energy 122:87-96
Congiu M et al (2016a) Cobalt sulfide as counter electrode in p-type dye-sensitized solar cells. ChemistrySelect 1(11):2808-2815

Congiu M et al (2016b) Cu2-xS films as counter-electrodes for dye solar cells with ferrocene-based liquid electrolytes. Thin Solid Films 612:22-28

De Rossi F et al (2013) Blending CoS and Pt for amelioration of electrodeposited transparent counterelectrodes and the efficiency of back-illuminated dye solar cells. J Mater Chem A 1(41):12941

De Vos A (1980) Detailed balance limit of the efficiency of tandem solar cells. J Phys D Appl Phys 13(5):839

Dessi A et al (2014) Organic dyes with intense light absorption especially suitable for application in thin-layer dye-sensitized solar cells. Chem Commun 50(90):13952-13955

Dougan WK, Wilson AL (1974) The absorptiometric determination of aluminium in water. A comparison of some chromogenic reagents and the development of an improved method. Analyst 99(1180):413-430

Fabregat-Santiago F et al (2011) Characterization of nanostructured hybrid and organic solar cells by impedance spectroscopy. Phys Chem Chem Phys 13(20):9083

$\mathrm{Fu} \mathrm{N}$ et al (2012) Electrodeposition of platinum on plastic substrates as counter electrodes for flexible dye-sensitized solar cells. J Phys Chem C 116(4):2850-2857

Fukushima J, Hayashi Y, Takizawa H (2013) Structure and magnetic properties of FeA12O4 synthesized by microwave magnetic field irradiation. Journal of Asian Ceramic Societies 1(1):41-45

Gibson E (2013) A et al. Dye sensitised solar cells with nickel oxide photocathodes prepared via scalable microwave sintering Pccp 15(7):2411-2420

He J et al (2000) Dye-sensitized nanostructured tandem cell-first demonstrated cell with a dye-sensitized photocathode. Sol Energy Mater Sol Cells 62(3):265-273

Heo JH et al (2012) Sb 2 S 3 -sensitized photoelectrochemical cells: open circuit voltage enhancement through the introduction of poly-3-hexylthiophene interlayer. J Phys Chem C 116(39):20717-20721

Hirschorn B et al (2010) Determination of effective capacitance and film thickness from constant-phase-element parameters. Electrochim Acta 55(21):6218-6227

Jastrzębska I et al (2015) Crystal structure and Mössbauer study of FeAl2O4. Nukleonika 60(1):47-49

Kleiman-Shwarsctein A et al (2010) Electrodeposited aluminumdoped ??-Fe2O3 photoelectrodes: experiment and theory. Chem Mater 22(2):510-517

Kumar, P. et al. 2012 Photoelectrochemical Hydrogen Generation using Al Doped Nanostructured Hematite Thin Films BT Chemistry of Phytopotentials: Health, Energy and Environmental Perspectives. In: Khemani, D. L.; Srivastava, M. M.; Srivastava, S. (Eds.). Berlin, Heidelberg: Springer Berlin Heidelberg. p. 197-200.

Lan JL et al (2010) The simple and easy way to manufacture counter electrode for dye-sensitized solar cells. Curr Appl Phys 10(2):S168-S171

Lin Y et al (2011) Hematite-based solar water splitting: challenges and opportunities. Energy \& Environmental Science 4(12): 4862

Lin Y et al (2012) Growth of p-type hematite by atomic layer deposition and its utilization for improved solar water splitting. J Am Chem Soc 134(12):5508-5511 
Mathew S et al (2014) Dye-sensitized solar cells with $13 \%$ efficiency achieved through the molecular engineering of porphyrin sensitizers. Nat Chem 6(3):242-247

Miller EL et al (2004) Low-temperature reactively sputtered iron oxide for thin film devices. Thin Solid Films 466(1-2):307313

Novelli V et al (2015) Electrochemical characterization of rapid discharge sintering (RDS) $\mathrm{NiO}$ cathodes for dyesensitized solar cells of p-type. Am J Anal Chem 6(2): 176-187

O'regan B, Gräzel M (1991) A low-cost, high-efficiency solar cell based on dye-sensitized. Nature 353:737-740

Rashid NM, Kishi N, Soga T (2016) Effects of nanostructures on iron oxide based dye sensitized solar cells fabricated on iron foils. Mater Res Bull 77:126-130

Shinde SS et al (2011) Physical properties of hematite $\alpha$-Fe2O3 thin films: application to photoelectrochemical solar cells. $\mathrm{J}$ Semicond 32(1):13001
Shull KE, Guthan GR (1967) Rapid modified eriochrome cyanine $\mathrm{R}$ method for determination of aluminum in water. Journal (American Water Works Association) 59(11):1456-1468

Tamirat AG et al (2016) Using hematite for photoelectrochemical water splitting: a review of current progress and challenges. Nanoscale Horizons 1(4):243-267

Trang Pham, T. T. et al. (2014) Reducing mass-transport limitations in cobalt-electrolyte-based dye-sensitized solar cells by photoanode modification. Chem Phys Chem. Anais

Wang H, Hu YH (2012) Graphene as a counter electrode material for dye-sensitized solar cells. Energy \& Environmental Science 5(8):8182

Wang M et al (2009) CoS supersedes Pt as efficient electrocatalyst for triiodide reduction in dye-sensitized solar cells. J Am Chem Soc 131(44):15976-15977

Willis AL et al (2007) Metal acetylacetonates as general precursors for the synthesis of early transition metal oxide nanomaterials. Journal of Nanomaterials, v 2007 